УДК 621.396 .67

DOI: https://doi.org/10.26642/ten-2020-1(85)-177-183

Н.М. Каращук, к.т.н., ст. викладач Житомирський військовий інститут імені С.П. Корольова

В.П. Манойлов, Д.т.н., проф.

Т.М. Нікітчук, к.т.н., доц.

В.В. Чухов, к.т.н., доц.

П.П. Мартинчук, ст. викладач

Державний університет «Житомирська політехніка»

\title{
Рупорна антена на основі заграничного прямокутного хвилеводу із частковим діелектричним заповненням та петлею зв'язку
}

\begin{abstract}
Проведено розгляд характеристик рупорної антени на основі заграничного прямокутного хвилеводу із частковим діелектричним заповненням (ЧДЗ) та петлею зв'язку.

Для експериментального вимірювання коефіиієнта підсилення антени обрано дзеркальний метод. Відповідно запропоновано застосування для аналізу таких антен резонансну модель (прямокутний резонатор). Отримано формулу для розрахунку вхідного опору петлі зв'язку, яка збуджує резонатор. Формула враховує додатковий опір у колі петлі, який з'являється через збудження електромагнітного поля в резонаторі. Це дозволяє розраховувати коефіцієнт стоячої хвилі (КСХ) та коефіцієнт підсилення антени зокрема.

Проведено експериментальне вимірювання залежностей КСX від зміни довжини, товщчин діелектричних пластин з відносною діелектричною проникністю $\varepsilon=8,5$ та діаметра провода петлі зв'язку у прямокутному хвилеводі розмірами 7,2×3,4 мм для хвилі типу $H_{10}$. Пропонуються оптимальні розміри діелектричних пластин та положення петлі зв'язку для покращення узгодження антени.

Наведено результати експериментального вимірювання коефіцієнта підсилення антени, які не мають суттєвих розбіжностей з розрахунками. Розглянуті залежності коефіцієнта підсилення антени мають резонансний характер, щцо вказує на правильність застосування для аналізу таких випромінювачів резонансної моделі.
\end{abstract}

Ключові слова: часткове діелектричне заповнення; прямокутний хвилевід; прямокутний резонатор; петля зв 'язку; узгодження; коефіцієнт стоячої хвилі.

Актуальність теми. Одним із перспективних типів антен, які застосовуються в діапазоні надвисоких частот (НВЧ), є рупорні антени [1-3]. Основними перевагами таких антен є діапазонність, простота конструкції, надійність експлуатації. Особливо важливою є діапазонність, яка необхідна для підвищення інформативності радіоліній різного призначення. Кількісною мірою діапазонності антени $\epsilon$ інтервал частот, в якому іiі параметри знаходяться в заданих межах. Вона часто визначається за коефіцієнтом відбиття [4], який являє собою відношення амплітуди відбитої хвилі до амплітуди падаючої хвилі. Крім того, вважається, що спрямовані властивості антени (ширина і форма головного максимуму, рівень бокових пелюсток діаграми спрямованості (ДС)) в широкому інтервалі частот змінюються в допустимих межах. Також перспективним для рупорних антен є зменшення їх геометричних розмірів за рахунок застосування часткового діелектричного заповнення в хвилеводі живлення [5]. Тому розрахунок рупорних антен, що живляться зокрема заграничними прямокутними хвилеводами із ЧДЗ, є актуальною задачею.

Аналіз останніх досліджень та публікації, на які спирається автор. На теперішній час є достатньо багато публікацій про рупорні антени [3, 6-13]. Необхідно зауважити, що більша частина досліджень спрямованих властивостей рупорних антен основана на застосуванні формули Кірхгофа, що $\epsilon$ математичним формулюванням принципу Гюйгенса-Френеля. Рішення знаходиться в наближенні Кірхгофа, де поле антени визначається в дальній зоні за розподілом поля в ії апертурі. Порівняння строгого та наближеного рішень у межах головної та ближчих бокових пелюсток дає хороші результати.

У зв'язку з мінітюаризацією радіоелектронної апаратури НВЧ діапазону постало питання про зменшення розмірів пристроїв, що випромінюють, за збереження їх характеристик. Було запропоновано конструювання антен на основі частково заповнених діелектриком хвилеводів, зокрема заграничних, що дозволило зменшити геометричні розміри випромінювачів. Частково заповнені хвилеводи дозволили суттєво покращити технічні характеристики антен, а також створити нові функціональні вузли [5].

Метою статті є розгляд характеристик рупорної антени зменшених геометричних розмірів за рахунок часткового діелектричного заповнення заграничного прямокутного хвилеводу живлення, що збуджується петлею зв'язку.

(C) Н.М. Каращук, В.П. Манойлов, Т.М. Нікітчук, В.В. Чухов, П.П. Мартинчук, 2020 
Викладення основного матеріалу. Антена складається із пірамідального рупора 1, до якого підключений заграничний прямокутний хвилевід 2. У хвилеводі 2 розташовані дві прямокутні діелектричні пластини 3 , що примикають до його бокових стінок та петля зв'язку 4, яка є продовженням коаксіальної лінії живлення 5 (рис. 1).
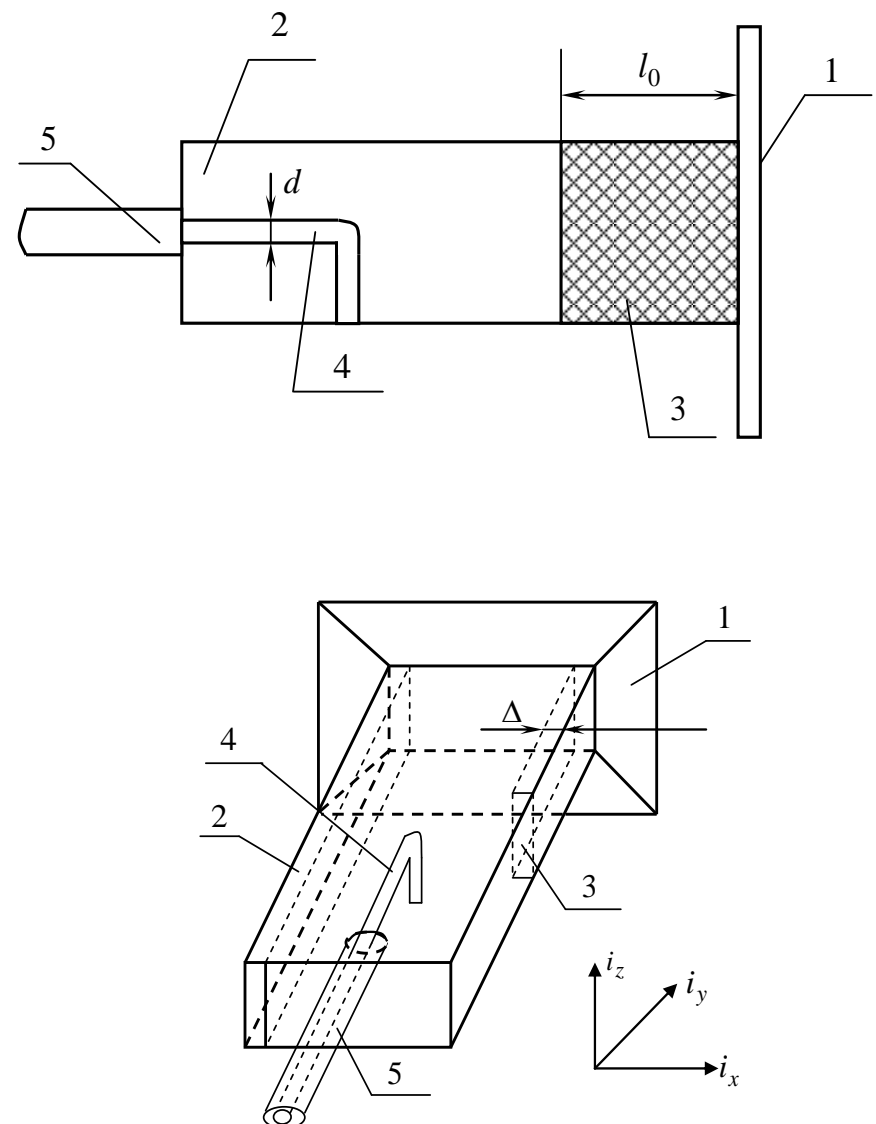

Рис. 1. Рупорна антена на основі заграничного прямокутного хвилеводу із частковим діелектричним заповненням та петлею зв 'язку

На рисунку 1 позначено $d$ - діаметр провода петлі зв'язку, $l_{0}$ - довжина діелектричної пластини, $\Delta-$ ширина діелектричної пластини.

Однією із основних характеристик будь-якої антени є коефіцієнт підсилення $[14,15]$, який достатньо точно можна виміряти за допомогою вимірювальної лінії дзеркальним методом [4]. Схема вимірювання коефіцієнта підсилення за допомогою дзеркального методу наведена на рисунку 2.

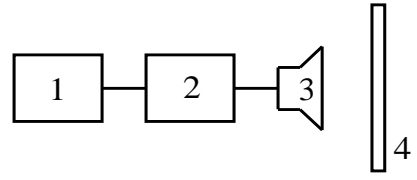

Рис. 2. Схема вимірювання коефіцієнта підсилення антени

У склад схеми входять генератор НВЧ 1, вимірювальна лінія 2, досліджувальна антена 3, плоский екран 4.

Перед початком вимірювань проводиться налаштування антенно-фідерної системи, а саме так, щоб коефіцієнт стоячої хвилі (КСХ) у вимірювальній лінії був близьким до одиниці. Потім перед антеною 3 на відстані $r \geq \frac{r_{\min }}{2}$ встановлюється плоский металевий екран, площина якого перпендикулярна напрямку головного максимуму ДС антени 3, а розміри такі, що із центра антени екран видно під тілесним кутом, не меншим за тілесний кут, що займає головна пелюстка діаграми спрямованості антени. Екран 4 порушує 
узгодження в лінії. 3 допомогою вимірювальної лінії 2 визначається КСХ, після установки екрану 4. За розузгодженням можна розрахувати коефіцієнт підсилення антени, застосовуючи такий вираз [4]:

$$
G=\frac{4 \pi r}{\lambda} \frac{\left|z_{H}\right|}{R_{a}},
$$

де $r$ - відстань від антени до екрана, м;

$\lambda$ - довжина хвилі в повітрі, м;

$z_{н}$ - опір навантаження, Ом;

$R_{a}-$ вхідний опір антени, Ом.

Величини $R_{a}$ та $z_{н}$ можуть бути знайдені шляхом вимірювання вхідного опору антени за наявності екрану та без нього. Значення величини опору навантаження можна визначити за формулою [4, с. 208].

Таким чином, дзеркальний метод дає можливість визначити коефіцієнт підсилення антени або за величиною розстроювання КСХ, через наявність екрану або активною складовою вхідного опору антени без екрану. Для підвищення точності вимірювання КСХ можна застосувати метод неузгодженого Т-мосту, що описаний в роботі [16].

Вимірювання коефіцієнта підсилення антени 3 допомогою плоского екрану можна наближено представити як прямокутний резонатор [17]. Це дозволяє розрахувати характеристики такої антени та порівняти їх з експериментальними.

Збудження прямокутного резонатора з допомогою петлі зв'язку детально описано в роботі [4]. Застосуємо деякі вирази з цієї роботи.

Нехай всередину резонатора введена петля зв'язку, через яку протікає струм. Якщо на затискачах петлі зв'язку 4, розміри якої малі порівняно з довжиною хвилі, діє стороння напруга, $U$, то, відповідно до закону Кірхгофа, вираз для іiі розрахунку можна записати таким чином:

$$
U=R I+\frac{d \Phi}{d t},
$$

де $R$ - власна активна складова опору петлі зв'язку, Ом;

$\Phi$ - магнітний потік через площу петлі $S$, Вб;

$I$ - струм, що протікає через петлю зв'язку, А.

Після ділення на струм, отримуємо вхідний опір петлі зв'язку, який можна зазначити таким чином:

$$
Z_{\text {вx }}=R+j \omega \frac{\Phi}{I} .
$$

Збудження електромагнітного поля в резонаторі супроводжується появою в колі петлі додаткового опору, який дорівнює:

$$
\Delta Z=j \omega \frac{\Phi}{I},
$$

як для вимірювання коефіцієнта підсилення за допомогою плоского екрана.

Щоб визначити опір $\Delta Z$, проводиться розрахунок електромагнітного поля, що створене петлею зв'язку в резонаторі.

Магнітний потік через площу витка в першому наближенні дорівнює [14]:

$$
\Phi=\int_{S} \mu \bar{H} \overline{d S}=\int_{l} \bar{A} \overline{d l}
$$

де $\bar{A}$ - вектор-потенціал;

$l$ - довжина петлі, м.

Представимо вектор-потенціал шуканого поля вимушених коливань у резонаторі таким чином [14]:

$$
A(\bar{r}, t)=\sum_{v} e_{v}(t) \overline{A_{v}}(\bar{r})
$$

де $e_{v}(t)$ - невідомі коефіцієнти, що визначають інтенсивність різних типів полів, які збуджуються в резонаторі;

$v$ - тип власних коливань резонатора.

Заданий сторонній струм, який протікає по петлі зв'язку, можна розкласти в ряд за власними функціями $A_{v}(\bar{r})$. Тоді об'ємна густина струмів $i_{v}(t)$ буде дорівнювати [14]:

$$
i_{v}(t)=\frac{1}{V} \int_{V} \bar{j}(\bar{r}, t) \overline{A_{v}}(\bar{r}) d v,
$$

де $V$ - об'єм резонатора, м³.

Для визначення величини коефіцієнтів $e_{v}$ можна застосувати вираз, наведений в роботі [14] в такому вигляді: 


$$
e_{v}=\frac{1}{\varepsilon} \frac{I_{\mathrm{v}}}{\omega_{v}^{2}-\omega^{2}+j \frac{\omega \omega_{v}}{\varphi_{v}}},
$$

де $\omega_{v}$ - частота генератора для $v$-го типу коливань, рад/с;

$\omega$ - частота коливання в резонаторі, рад/c;

$\varphi_{v}-$ добротність резонатора, що відповідає $v$-му типу коливань;

$\varepsilon$ - відносна діелектрична проникність діелектричних пластин.

Позначивши далі $\left(\omega-\omega_{v}=\Delta \omega\right)$, і вважаючи, що $\left(\Delta \omega / \omega_{v} \leq 1\right)$ із рівняння $(8)$, можна отримати наближену рівність:

$$
e_{v m} \approx-\frac{j}{\omega_{v}^{2} \varepsilon} \frac{I_{v} \varphi_{v}}{1+j 2 \varphi_{v} \frac{\Delta \omega}{\omega_{v}}} .
$$

Звідси випливає, що величина $e_{v m}$ досягає максимуму, якщо частота коливань джерела $\omega$ збігається 3 власною частотою $\omega_{v}$ та зменшується за мірою відхилення $\omega$ від $\omega_{v}$. Таким чином, залежність амплітуди коливань $v$-го типу в резонаторі від частоти джерела має типовий резонансний характер.

Підставимо значення $e_{v m}$ у рівняння (6), в результаті маємо:

$$
\begin{aligned}
& \bar{A}(\bar{r}, t)=-\frac{j}{\varepsilon_{v m}^{2}} \bar{I}_{v m} \varphi_{v m} \bar{A}_{v m}(\bar{r}) e^{j \omega t}+ \\
& +\frac{1}{\varepsilon} \sum_{v} \frac{I_{v m}}{\left(\omega_{v m}^{2}-\omega^{2}\right)+j \frac{\omega \omega_{v}}{\varphi_{v}}} \bar{A}_{v m}(\bar{r}, t) e^{j \omega t} .
\end{aligned}
$$

Потік $\Phi$ через петлю зв’язку рівний, відповідно до виразу (5):

$$
\Phi \cong \int_{l} \bar{A} d l=\sum_{v} e_{v}(t) \int_{l} \bar{A}_{v}(\bar{r}) \overline{d l}
$$

Як видно з формули (11), $\int_{l} \bar{A} d l$ являє собою магнітний потік, що відповідає $v$-му власному коливанню, коли $e_{v}(t)=1$. Цю величину можна розглядати як коефіцієнт взаємоіндукції петлі зв’язку 3 магнітним полем $v$-го власного коливання.

Ввівши позначення:

$$
M_{v} \cong \int_{l} \overline{A_{v}}(\bar{r}) \overline{d l},
$$

перепишемо рівняння (2) у такому вигляді:

$$
U=R I+\sum_{v} M_{v} \frac{d e_{v}(t)}{d t} .
$$

Вважаючи, що струм в петлі зв'язку однаковий у всіх іiі точках, та використовуючи вираз (12), отримаємо [14]:

$$
Z_{B x}=\frac{U}{I}=R+\sum_{v} \frac{j \omega M_{v}^{2}}{e_{v}\left(\omega_{v}^{2}-\omega^{2}+\frac{j \omega \omega_{v}}{\varphi_{v}}\right)} .
$$

Вираз (14) дає можливість визначити опір петлі зв'язку, яка збуджує резонатор. Перший доданок у виразі (14) являє собою активний опір, який наводиться полем резонатора та є практично реактивним.

Якщо виток петлі зв'язку розташований в точці $x=a / 2$ та якщо площина витка нормальна до $\bar{i}_{x}$, а сам він достатньо малий, то [14]:

$$
\left|M_{v}\right|=2 \pi \frac{S}{a},
$$

де $a$ - розмір широкої стінки прямокутного хвилеводу, м.

В цьому випадку, як показано в роботі [14]:

$$
R_{\text {рез }}=\frac{1}{a}\left(\frac{2 \pi S}{a}\right)^{2} \frac{\varphi_{v}}{\omega_{v}^{2} a^{3}} .
$$

де $\omega_{v}=\omega_{101}$. 
Зазначений метод дозволяє знайти всі необхідні дані для розрахунку $Z_{\text {вx }}$, а потім і коефіцієнта підсилення вказаної антени.

На рисунку 3 наведено результати експериментального дослідження залежностей коефіцієнта стоячої хвилі $K_{c}$ від довжини та товщини діелектрика.
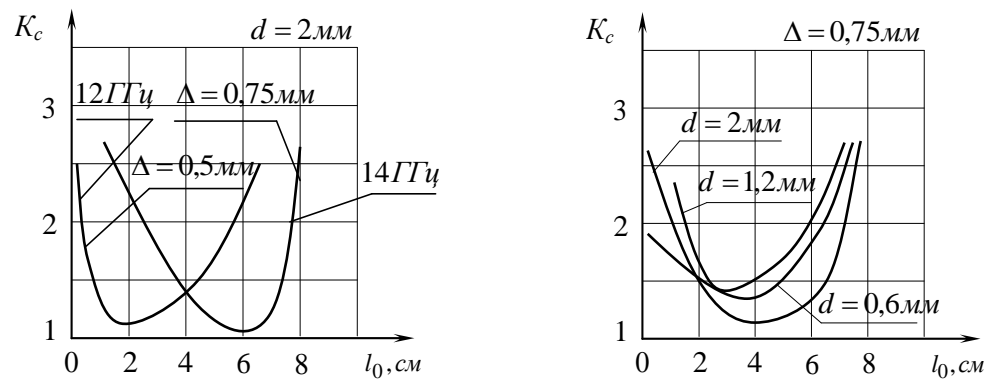

Рис. 3. Графіки залежностей коефіцуієнта стоячої хвилі від довжини $l_{0}$ i товщчин $\Delta$ діелектрика

Відносна діелектрична проникність пластин, що примикають до вузьких стінок прямокутного хвилеводу розмірами $7,2 \times 3,4$ мм, дорівнює $\varepsilon=8,5$. Дослідження проводилися за різної довжини діелектрика $l_{0}$ та його товщини $\Delta$, діаметра провода петлі зв'язку $d$ для хвилі типу $H_{10}$ (рис. 3 ).

Результати експерименту дозволяють зробити висновок про різку залежність узгодження антени від товщини діелектрика та відстані між петлею зв'язку і пластинами.

Кращі результати по узгодженню отримано у разі збігу діаметра провода петлі зв'язку із діаметром внутрішнього провідника коаксіальної лінії живлення та товщини пластин $\Delta=0,75$.

На рисунку 4 наведено розрахункові характеристики коефіцієнта підсилення антени на середній частоті їі діапазону 12-15 ГГц (1 - розрахунок) для площин $a)$ Н і б) Е та виміряні дзеркальним методом $(2$ - експеримент). Результати розрахунків та експериментальних досліджень суттєвих розбіжностей не мають.

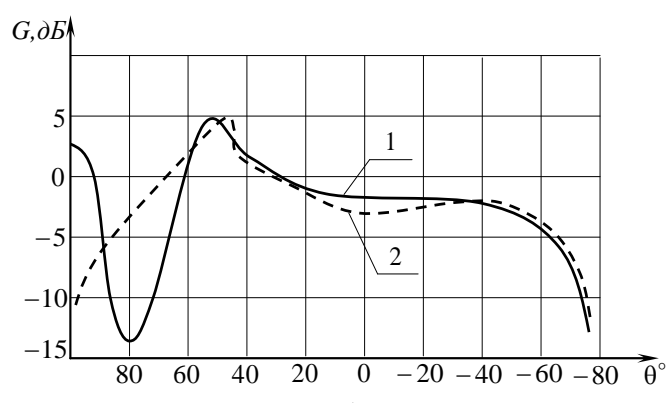

a)

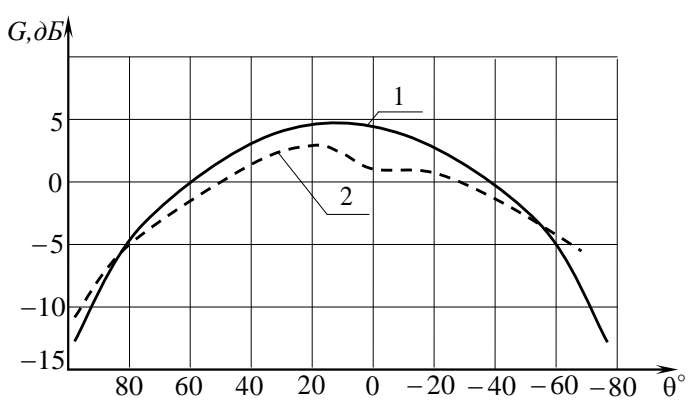

б)

Рис. 4. Коефіцієєнт підсилення антени в площчинах а) Н та б) E

Висновки та перспективи подальших досліджень. Проведені теоретичні та експериментальні дослідження рупорної антени на основі заграничного прямокутного хвилеводу із частковим діелектричним заповненням та петлею зв'язку показують можливість створення малогабаритного випромінювача для використання в різних радіотехнічних системах НВЧ діапазону. Застосування заграничного хвилеводу дозволяє в декілька разів зменшити розміри антени, що дуже важливо для зменшення ваги радіотехнічної апаратури.

Як видно із розглянутих залежностей коефіцієнта підсилення антени, вони мають резонансний характер, що вказує на правильність застосування для аналізу таких випромінювачів резонансної моделі. Застосування для вимірювання характеристик рупорної антени дзеркального методу дозволяє просто та достатньо точно визначити всі характеристики випромінювача, вимірюючи тільки його КСХ.

Достовірність отриманих виразів підтверджена збіжністю за одиницями вимірювання, а також шляхом порівняння з результатами експериментальних досліджень.

Практичним значенням результатів досліджень $€$ можливість синтезу (проєктування) антен 3 покращеним узгодженням та зменшеним поперечним перерізом хвилеводу з незмінних його електричних розмірів. 
Перспективи подальших досліджень у цьому напрямі полягають у розв'язанні задачі оптимізації положення петлі зв'язку та параметрів ЧДЗ з метою мінімізації коефіцієнта стоячої хвилі у заданому діапазоні робочих частот.

\section{Список використаної літератури:}

1. Неганов В.Я. Устройства СВЧ и антенны / В.Я. Неганов, Д.С. Клюев, Д.П. Табаков. - М. : Ленанд, 2016. -728 с.

2. Виноградов А.Ю. Устройства СВЧ и малогабаритные антенны / А.Ю. Виноградов, Р.В. Кабетов, A.M. Сомов. - М. : Горячая линия - Телеком, 2012. - 440 с.

3. Манойлов В.П. Широкосмугові рупорні антени зі складною формою поперечного перерізу : монографія / В.П. Манойлов, В.В. Павлюк, Р.Л. Ставісюк. - Житомир : Видавець О.О. Свенок, 2016. - 212 с.

4. Фрадин А.3. Измерения параметров антенно-фидерных устройств / А.3. Фрадин, Е.В. Рыюжков. - М. : Связь, 1972. $-362 \mathrm{c}$

5. Веселов Г.И. Слоистые металодиэлектрические волноводы / Г.И. Веселов. - М. : Радио и связь, 1988. -247 с.

6. Сомов А.М. Проектирование антенно-фидерных устройств / А.М. Сомов, Р.В. Кабетов. - М. : Горячая линия Телеком, 2015. - $500 \mathrm{c}$.

7. A Tunable Compact Polarizer in a Circular Waveguide / A.A. Kirilenko, S.O. Steshenko, V.N. Derkach, Y.M. Ostryzhnyi // IEEE Trans. Microwave Theory Tech. - 2019. - Vol. 67, Issue 2. - P. 592-596.

8. Mospan L. Singlet Formed by Two Transversal Ridges in a Rectangular Waveguide from the Spectral Theory Point of View / L.Mospan, S.Prikolotin, A.Kirilenko // European Microwave Conference (EuMC 2013) : proc. (Nuremberg, Germany, 6-10 Oct. 2013). - P. 628-631.

9. Penkin D.Yu. Analysis of energy characteristics of the transversal slot in a wide wall of a rectangular waveguide with local dielectric inclusion / D.Yu. Penkin, L.P. Yatsuk // Telecommunications and Radio Engineering. - 2014. Vol. 73 (8). - P. 669-680.

10. Radiation and scattering of electromagnetic waves by a multi-element vibrator-slot structure in a rectangular waveguide / S.L. Berdnik, V.A. Katrich, M.V. Nesterenko and other // IEEE Trans. Antennas Propag. - 2015. Vol. 63. - P. 4256-4259.

11. Skresanov V.N. Circular Layered Waveguide Use for Wideband Complex Permittivity Measurement of Lossy Liquids / V.N. Skresanov, Z.E. Eremenko, E.S. Kuznetsova // IEEE Transactions on Instrumentation and Measurement. - 2014. - Vol. 63, № 3. - P. 694-701.

12. Еременко 3.E. Распространение волн в двухслойном запредельном волноводе с сильно поглощающей средой в диапазоне 5...30 ГГц / 3.Е. Еременко, Е.С. Кузнеиова // Радиофизика и электроника. - 2016. - Т. 7 (21), № 3. - С. 74-82.

13. Манойлов В.П. Дослідження електродинамічних характеристик антени у вигляді відкритого кінця прямокутного хвилеводу із частковим діелектричним заповненням та штирем збудження / В.П. Манойлов, B.B. Чухов, Н.М. Карашук // Вісник ЖДТУ. Технічні науки. - 2019. - № 1 (83). - С. 214-218.

14. Гольдштейн Л.Д. Электромагнитные поля и волны / Л.Д. Гольдштейн, Н.В. Зернов. - М. : Сов. радио, 1971. $615 \mathrm{c}$

15. Устройства СВЧ и КВЧ-диапазонов / Ю.А. Иларионов, А.С. Раевский, С.Б. Раевский, А.Ю. Седаков. - М. : Радиотехника, 2013. - $752 \mathrm{c}$.

16. Метод вимірювання ефективної діелектричної прониконості частково-заповнених хвилеводів за допомогою неузгодженого Т-мосту / Н.М. Каращук, В.П. Манойлов, О.Л. Сидорчук та ін. // Вісник НТУУ «КПІ». Раідотехніка. Радіоапаратобудування. - 2019. - № 78. - С. 6-12.

17. Вайнштейн В.А. Электромагнитные волны / В.А. Вайнштейн. - М. : Радио и связь, 1988. -436 с.

\section{References:}

1. Neganov, V.Ya., Klyuev, D.S. and Tabakov, D.P. (2016), Ustroystva SVCh i antenny, Lenand, M., 728 p.

2. Vinogradov, A.Yu., Kabetov, R.V. and Somov, A.M. (2012), Ustroystva SVCh i malogabaritnye antenny, Goryachaya liniya - Telekom, M., 440 p.

3. Manojlov, V.P., Pavljuk, V.V. and Stavisjuk, R.L. (2016), Shyrokosmugovi ruporni anteny zi skladnoju formoju poperechnogo pererizu, monografija, Vydavec' O.O. Jevenok, Zhytomyr, $12 \mathrm{p}$.

4. Fradin, A.Z. and Ryzhkov, E.V. (1972), Izmereniya parametrov antenno-fidernykh ustroystv, Svyaz', M., 362 p.

5. Veselov, G.I. (1988), Sloistye metalodielektricheskie volnovody, Radio i svyaz', M., 247 p.

6. Somov, A.M. and Kabetov, R.V. (2015), Proektirovanie antenno-fidernykh ustroystv, Goryachaya liniya - Telekom, M., 500 p.

7. Kirilenko, A.A., Steshenko, S.O., Derkach, V.N. and Ostryzhnyi, Y.M. (2019), "A Tunable Compact Polarizer in a Circular Waveguide», IEEE Trans. Microwave Theory Tech, Vol. 67, Issue 2, pp. 592-596.

8. Mospan, L., Prikolotin, S., and Kirilenko, A. (2013), «Singlet Formed by Two Transversal Ridges in a Rectangular Waveguide from the Spectral Theory Point of View», European Microwave Conference (EuMC 2013), proc. Nuremberg, Germany, 6-10 Oct. 2013, pp. 628-631.

9. Penkin, D.Yu. and Yatsuk, L.P. (2014), «Analysis of energy characteristics of the transversal slot in a wide wall of a rectangular waveguide with local dielectric inclusion», Telecommunications and Radio Engineering, Vol. 73 (8), pp. 669-680.

10. Berdnik, S.L., Katrich, V.A., Nesterenko, M.V. and other (2015), «Radiation and scattering of electromagnetic waves by a multi-element vibrator-slot structure in a rectangular waveguide», IEEE Trans. Antennas Propag., Vol. 63, pp. 4256-4259. 
11. Skresanov, V.N., Eremenko, Z.E. and Kuznetsova, E.S. (2014), «Circular Layered Waveguide Use for Wideband Complex Permittivity Measurement of Lossy Liquids», IEEE Transactions on Instrumentation and Measurement, Vol. 63, No. 3, pp. 694-701.

12. Eremenko, Z.E. and Kuznetsova, E.S. (2016), «Rasprostranenie voln v dvukhsloynom zapredel'nom volnovode s sil'no pogloshchayushchey sredoy v diapazone 5...30 GGts», Radiofizika i elektronika, T. 7 (21), No. 3,pp. 74-82.

13. Manojlov, V.P., Chuhov, V.V. and Karashhuk, N.M. (2019), «Doslidzhennja elektrodynamichnyh harakterystyk anteny u vygljadi vidkrytogo kincja prjamokutnogo hvylevodu iz chastkovym dielektrychnym zapovnennjam ta shtyrem zbudzhennja», Visnyk ZhDTU. Tehnichni nauky, No. 1 (83), pp. 214-218.

14. Gol'dshteyn, L.D. and Zernov, N.V. (1971), Elektromagnitnye polya $i$ volny, Sov. radio, M., 615 p.

15. Ilarionov, Yu.A., Raevskiy, A.S., Raevskiy, S.B. and Sedakov, A.Yu. (2013), Ustroystva SVCh i KVCh-diapazonov, Radiotekhnika, M., 752 p.

16. Karashhuk, N.M., Manojlov, V.P., Sydorchuk, O.L. and other (2019), «Metod vymirjuvannja efektyvnoi' dielektrychnoi' pronykonosti chastkovo-zapovnenyh hvylevodiv za dopomogoju neuzgodzhenogo T-mostu», Visnyk NTUU «KPI», Raidotehnika. Radioaparatobuduvannja, No. 78, pp. 6-12.

17. Vaynshteyn, V.A. (1988), Elektromagnitnye volny, Radio i svyaz', M., 436 p.

Каращук Наталія Миколаївна - кандидат технічних наук, старший викладач кафедри Житомирського військового інституту ім. С.П. Корольова.

Наукові інтереси:

- антени та техніка НВЧ.

E-mail:knm7@ukr.net.

http://orcid.org/0000-0002-5691-2098.

Манойлов В'ячеслав Пилипович - доктор технічних наук, професор, професор кафедри біомедичної інженерії і телекомунікацій Державного університету «Житомирська політехніка».

Наукові інтереси:

- електродинаміка;

- прилади НВЧ та антени;

- біомедичні прилади та системи.

E-mail: kaf.rrat@ukr.net.

http://orcid.org/0000-0001-6961-6995.

Нікітчук Тетяна Миколаївна - кандидат технічних наук, доцент, завідувач кафедри біомедичної інженерії і телекомунікацій Державного університету «Житомирська політехніка».

Наукові інтереси:

- медичні прилади і системи;

- обробка фазових портретів пульсової хвилі;

- математичне моделювання.

E-mail: tnikitchuk@ukr.net.

http://orcid.org/0000-0002-9068-931X.

Чухов Владислав Вікторович - кандидат технічних наук, доцент, доцент кафедри біомедичної інженерії та телекомунікацій Державного університету «Житомирська політехніка».

Наукові інтереси:

- радіовимірювання;

- пристрої НВЧ та антени.

E-mail: mps_cvv@ukr.net.

http://orcid.org/0000-0001-7782-9077.

Мартинчук Петро Петрович - старший викладач кафедри біомедичної інженерії та телекомунікацій Державного університету «Житомирська політехніка».

Наукові інтереси:

- обробка сигналів у радіотехнічних системах;

- електро- та радіовимірювальні прилади.

E-mail: m_petro@ukr.net.

http://orcid.org/ 0000-0002-3220-6033.

Стаття надійшла до редакції 30.03.2020. 